\title{
Eagle's Syndrome Presenting As Unilateral Pain In The Anterolateral Neck And Referred Otalgia
}

\author{
Waseem Mehmood Nizamani, Ameet Jesrani, Mujtaba Khan, Kalthoum Tlili, Nader Al Khuraish, Kousar Magsi
}

ABSTRACT:

Eagles syndrome or stylohyoid syndrome is a rare condition where slender elongated temporal styloid process or ossified stylohyoid ligament manifest a wide range of symptoms including otalgia, dysphagia, foreign body sensation in throat, pain in retrogonia or along anterolateral neck. It occurs mostly unilaterally however bilateral cases are also reported. Multislice computed tomography with maximum intensity projections reconstructions is used for diagnosis and management purposes. It also aids to see its compressive effect on adjacent anatomical structures.

Key Words: Otalgia, Multislice Computed tomography, calcified stylohyoid ligament.

\section{INTRODUCTION:}

Styloid process is pointed bony projection in the tympanic part of temporal bone and it lies anterior to the stylomastoid foramen. In tonsillar fossa, it is deeply located between internal and external carotid arteries ${ }^{1}$. In adults normal length of styloid process varies from $2.0 \mathrm{cms}$ to $2.5 \mathrm{cms}^{2}$. Greater than $3.0 \mathrm{cms}$ is referred as elongated styloid process $\mathrm{s}^{3,4}$. Cylindrical elongated styloid process is implicated to in craniocaudal pain syndromes i.e, Eagle's syndrome ${ }^{5,6}$. Variation in length (Eagle's syndromes), Position of styloid process, postsurgical fibrosis of tonsils, infection or post trauma may cause symptoms. Eagle's syndrome is characterized by symptoms due to an elongated styloid process (greater than $3 \mathrm{cms}$ ) or a calcified stylohyoid ligament ${ }^{7}$. Clinical examination, craniocervical features, digital palpation of styloid process in tonsillar fossa. Radiological findings and lidocaine infiltration test confirms its diagnosis ${ }^{8}$. Surgical and conservative treatment can be done.

\section{CASE REPORT:}

An old male who presented with complain of left sided neck

- Waseem

ood Nizamani,

Prince Sultan Military Medical

I City Riyadh KSA

Ameet Jesrani,

I Sindh Institute Of Urology and Transplantation,

I Karachi PK

I Email: ameet.jesrani@yahoo.com

I Mujtaba Khan,

I Prince Sultan Military Medical

City Riyadh KSA

I Kalthoum Tlili,

Prince Sultan Military Medical

I City Riyadh KSA

I Nader Al Khuraish,

I Prince Sultan Military Medical

I City Riyadh KSA

I Kousar Magsi

I Sindh Institute Of Urology and Transplantation,

Karachi PK

I Received: 22-10-18

Accepted: 11-12-18 and ear pain which is increasing during swallowing, masticating and stretching head for two months. No history of head trauma or surgery was present. On clinical examination, a hard mass is seen in left submandibular mass and causing pain on inspection and palpation. No other oropharyngeal abnormality was seen. Unenhanced computed tomography confirmed the diagnosis of elongated styloid processes with their length reaching at the level of mandibular ramus and reaches the submandibular region (fig. 1 and 2). It approximately measures $4.5 \mathrm{cms}$. These are causing mild compression on carotid jugular complex. Patient was informed about his diagnosis and six months follow up was suggested.

\section{DISCUSSION:}

Styloid process is an elongated pointed bony outgrowth from lower part of temporal bone which moves downwards and anteriorly towards maxilla vertebra pharyngeal recess, carotid vasculature, internal jugular vein and cranial nerves. Embrologically styloid process and ligaments are derivatives of Reichert's cartilage of second brachial arch. It is derived from temporal bone ${ }^{9}$. Its apex is important due to its location between external and internal carotid arteries and facial nerve which runs anteriorly and medially to $\mathrm{it}^{2}$. Ligaments can mineralize because of their cartilaginous origin. Mineralization of styloid ligament results into symptoms first attributed by Dr. Watt Eagle, an otolaryngologist in $1937^{9}$. Styloid process and temporal bone has implicated in craniocervical pain syndromes. Symptoms occur secondary to variation in length, position of styloid process, postsurgical fibrosis infection and trauma. Elongated styloid is considered if its length is greater than $3 \mathrm{cms}^{10}$. Its cause in still unknown. Its incidence is $4 \%$ to $28 \%$ and is most commonly seen in women ${ }^{11}$. It includes the symptoms of pharyngeal pain, foreign body sensation, otalgia, dysphagia and odynophagia. There are two sub types of Eagle's syndrome, the classic styloid and stylocarotid artery syndrome ${ }^{1}$. The classic type usually occur after tonsillectomy and result into pharyngeal pain radiating to middle ear and mastoid region, foreign body sensation, otalgia, dysphagia and odynophagia ${ }^{12,7}$. Impingement of carotid artery by 
elongated styloid process and calcified stylohyoid ligament result into carotid artery syndrome. Internal carotid artery involvement occurs when styloid process is bent laterally and causes constant neck pain on turning the head, pain. Other related symptoms include globus sensation, tinnitus, headache and otalgia ${ }^{13}$. Ischemia in affected area of head and neck is also responsible for the pain ${ }^{14}$. Multiple imaging techniques (modalities) are useful in diagnosis of this syndrome. It mainly includes conventional lateral and anteroposterior (AP) radiographs of head and neck, Towne's view orthopantomograph and computed tomography. Best imaging modality is multi slice computed tomography and 3-Dimensional reconstruction to provide exact
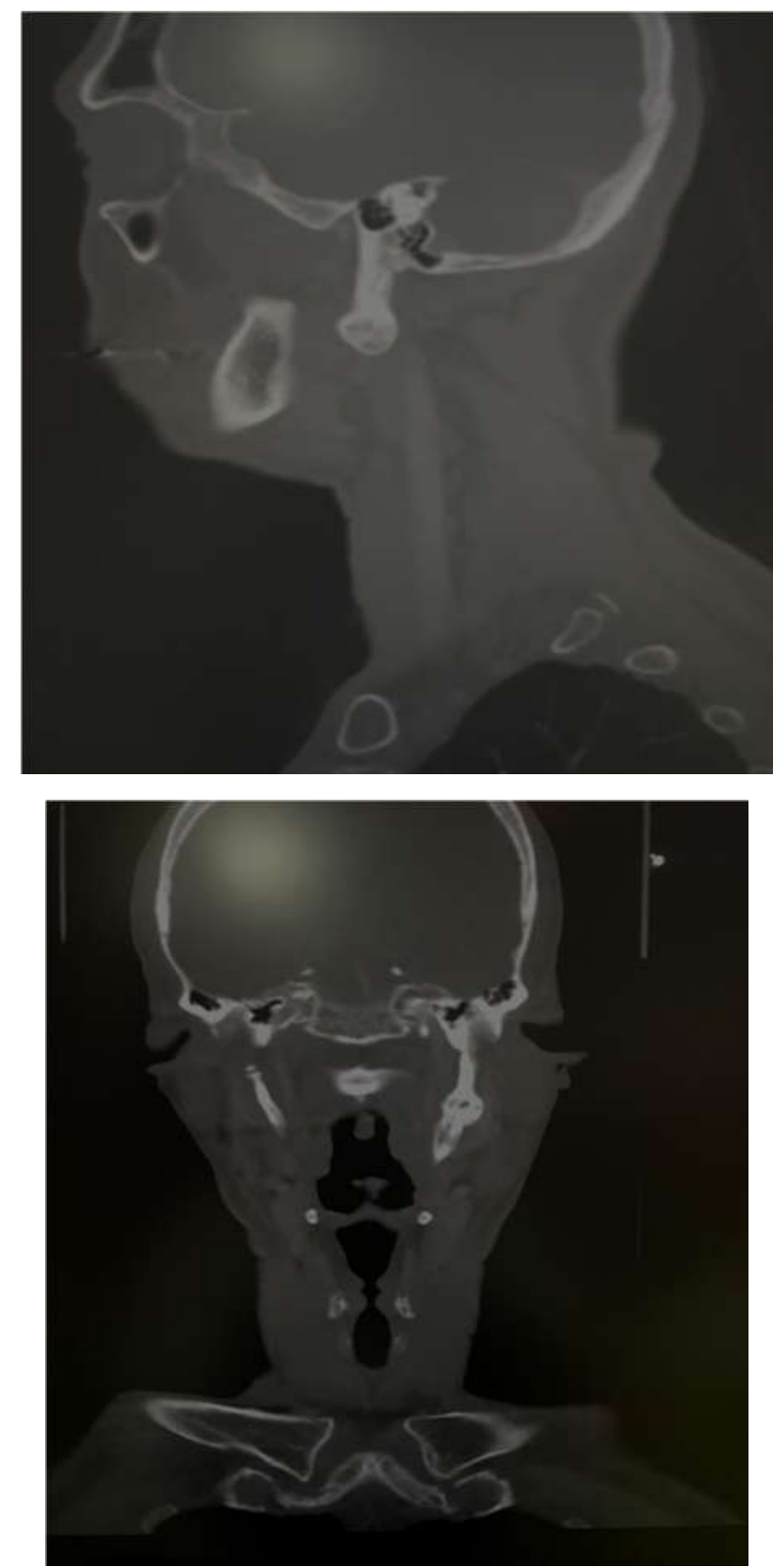

Fig.1, CT scan in bone window sagittal and coronal reformatted views demonstrating elongated styloid process causing mass effects over adjacent soft tissues.
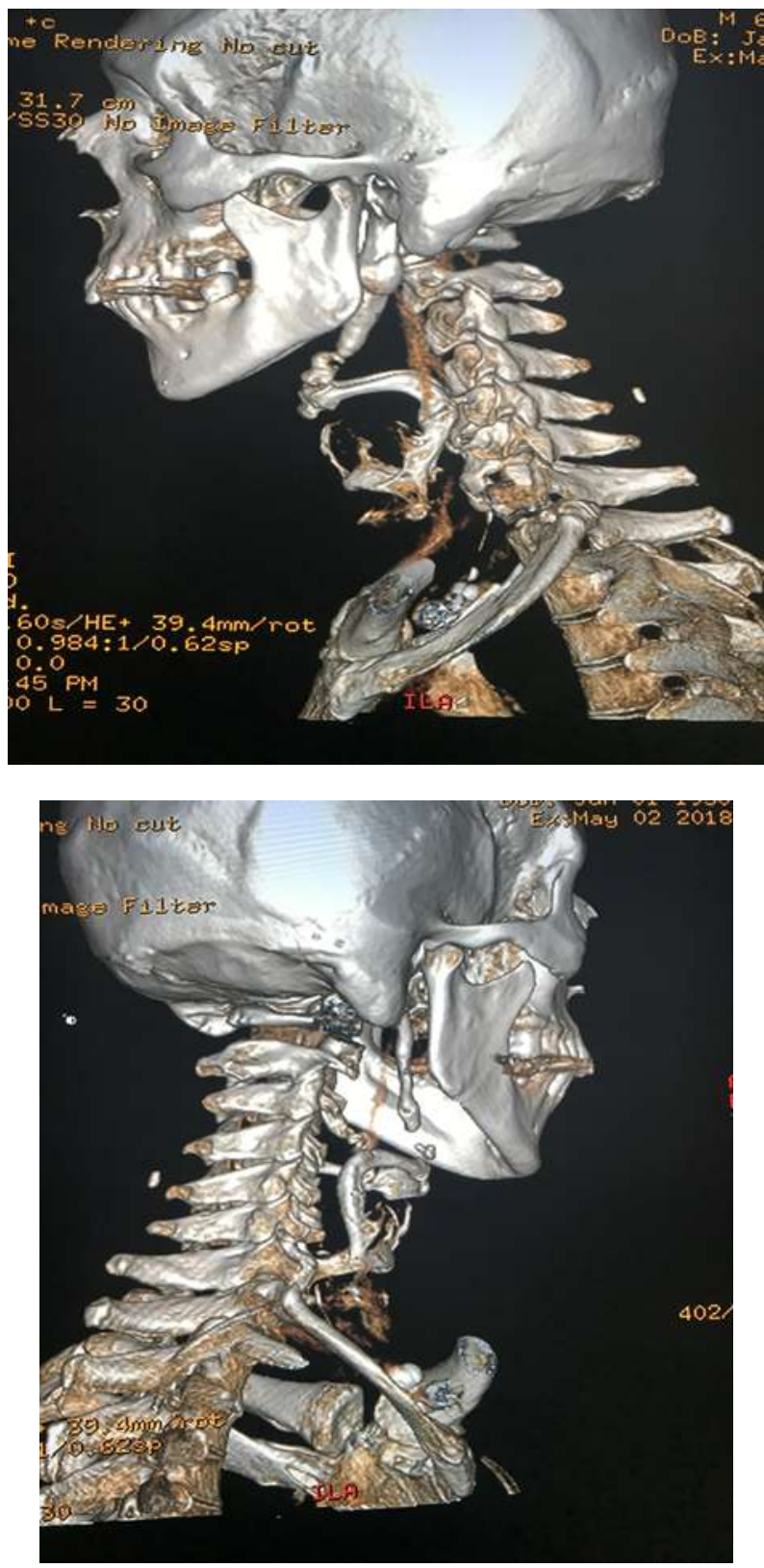

Fig.2, CT scan, Volume Rendered Surface Shaded Display, sagittal view showing elongated Styloid Process.

measurements of elongated styloid process and adjacent structure anatomy and normal variations, however, Orthopantomograph and $\mathrm{x} /$ ray plain radiographs can possibly misinterpret the diagnosis and are nonspecific ${ }^{15,16}$. Conservative and surgery are treatment options for symptomatic patients. Counseling and use of steroids, painkillers, local anesthesia and oral carbamazepine can be used in medical treatment. Chronic cases require surgical option for management ${ }^{17}$.

\section{CONCLUSION:}

Eagle's syndrome should be kept in differentials in patient 
presenting with orofacial or ear pain, tinnitus and globus sensation. Multislice computed tomography and 3dimensional reconstructions is the best investigation for confirmation of its diagnosis. Conservative treatment is preferred with follow-up twice a year.

\section{REFFERENCES:}

1. Gossman JR, Tarsitano JJ: The styloid-stylohoid syndrome. J Oral Surg 1977;35(7):555-60.

2. W. Eagle, "Elongated styloid process; further observations and a new syndrome," Archives of Olaryngology. 1948;47(5)630-40.

3. K.C. rasad,M. P.Kamath K. J. M. eddy,K. Raju, and S. Agrawal, "Elongated styloid process (Eagle's syndrome): a clinical study," Journal of Oral and Maxillofacial Surgery. 2002;60(20):171-175.

4. T. Jung, H. Tschernitschek, H. Hippen,B. Schneider, and L. Borcher, , "Elongated styloid process:when is it really elongated?" Dentomaxillofacial Radiology. 2004;33(2):11924.

5. Eagle WW:Elongated styloid process: Report of two cases Arch Otolaryngol. 1937;25(5):584-587.

6. Eagle WW: Elongated styloid process Otolarngol. 1958;67(2): 172-6

7. Monsor PA, Young WG Barnes PB. Styloid-stylohoid syndrome: a clinical update .Aust Dent J 1985;30:341-5.
8. Uludag IF, Ocek L, Zorlu Y, Uludag B (2013) Eagle syndrome: case report. Agri 2013;25(2): 87-89

9. Eagle WW. Elongated styloid processes. Arch Otolaryngol $1937 ; 25: 584-7$

10. Eagle WW. Elongated styloid process: symptoms and treatment Arch Otolaryngol 1958;64:172-6

11. Kuer JJ,Campbell JPS,McCarthy JF,Ralph WJ: the clinical significance of the elongated styloid process. Oral Surg Oral Med Oral Path.1986;61(4):399-404.

12. Manganaro AM, Nylander J. Eagle's syndrome: a clinical report and review of literature. Gen Dent 1998;46:282-4.

13. Slavin KV. Eagle syndrome: entrapment of the glossophayryngeal nerve? Case report and review of literature. J Neurosurg 2002;97:216-8.

14. Eagle WW. Elongated styloid process: further observations and a new syndrome," Archives of Otolaryngol, 1948;47:63040 .

15. Murtagh RD, Caracciol JT, Fernandez G.CT findings associated with eagle syndrome. AJNR Am J Neuroradiol 2001;22: 1401-2.

16. Sarvanlar A, Uzan L, Birol, Ozer T. Three - dimensional CT of Eagle's syndrome. Diagn Interv Radiol. 2005; 11: 206-9.

17. Ceylan A, Koybasioglu A, Celenk F, Yilmaz O, and Uslu S, "Surgical treatment of elongated styloid process: experience of 61 cases," Skull base. 2008;18(5):289-295. 